\title{
2017 Audited schedule of changes in net assets
}

\section{Ray Naegele}

See end of article for authors' affiliations.

The table below summarizes the association's financial status as of December 31, 2017. For a more complete audit report and related information, see the Audited Financial Statements (members only).
This report includes balance sheets, fund status reports, budgeted and actual revenues and expenditures, and a schedule of investments. Members may obtain a copy of the audit report from MLA headquarters.

Table 1 Medical Library Association schedule of changes in net assets by fund year ended December 31, 2017

\begin{tabular}{|c|c|c|c|c|c|c|}
\hline & $\begin{array}{c}\text { Net assets } \\
\text { January 1, } \\
2017\end{array}$ & $\begin{array}{l}\text { Contributions } \\
\text { and other } \\
\text { revenue }\end{array}$ & $\begin{array}{c}\text { Invest- } \\
\text { ment } \\
\text { income }\end{array}$ & $\begin{array}{l}\text { Net assets } \\
\text { released } \\
\text { from } \\
\text { restrictions }\end{array}$ & Expenses & $\begin{array}{c}\text { Net assets } \\
\text { December } \\
31,2017\end{array}$ \\
\hline \multicolumn{7}{|l|}{ Unrestricted net assets } \\
\hline General operating & $(\$ 208,798)$ & $\$ 2,626,097$ & $\$ 23,763$ & & $\$ 2,655,892$ & $(\$ 214,830)$ \\
\hline \multicolumn{7}{|l|}{ Other funds: } \\
\hline $\begin{array}{l}\text { Association } \\
\text { stabilization }\end{array}$ & $\$ 1,532,376$ & - & $\$ 211,058$ & - & - & $\$ 1,743,434$ \\
\hline Capital equipment & $\$ 2,228$ & - & - & - & - & $\$ 2,228$ \\
\hline Special purpose & $\$ 33,096$ & - & - & $\$ 103,016$ & $(\$ 136,112)$ & - \\
\hline Sections & $\$ 281,063$ & $\$ 49,051$ & - & - & $(\$ 40,541)$ & $\$ 289,573$ \\
\hline Total other funds & $\$ 1,848,763$ & $\$ 49,051$ & $\$ 211,058$ & $\$ 103,016$ & $(\$ 176,653)$ & $\$ 2,035,235$ \\
\hline \multicolumn{7}{|l|}{$\begin{array}{l}\text { Temporarily restricted net } \\
\text { assets }\end{array}$} \\
\hline $\begin{array}{l}\text { Ysabel Bertolucci MLA } \\
\text { Annual Meeting Grant } \\
\text { Endowment }\end{array}$ & $\$ 50$ & - & $\$ 4,751$ & (\$907) & - & $\$ 3,894$ \\
\hline $\begin{array}{l}\text { Estelle Brodman } \\
\text { Award for the } \\
\text { Academic Medical } \\
\text { Librarian of the Year } \\
\text { Endowment }\end{array}$ & $\$ 41,080$ & - & $\$ 4,859$ & $(\$ 500)$ & - & $\$ 45,439$ \\
\hline $\begin{array}{l}\text { Naomi C. Broering } \\
\text { Hispanic Heritage } \\
\text { Grant Endowment }\end{array}$ & $\$ 1,006$ & - & $\$ 4,201$ & (\$981) & - & $\$ 4,226$ \\
\hline $\begin{array}{l}\text { Lois Ann Colaianni } \\
\text { Award for Excellence } \\
\text { and Achievement in } \\
\text { Hospital Librarianship } \\
\text { Endowment }\end{array}$ & $\$ 9,569$ & - & $\$ 2,516$ & $(\$ 500)$ & - & $\$ 11,585$ \\
\hline $\begin{array}{l}\text { Consumer Health } \\
\text { Librarian of the Year } \\
\text { Award }\end{array}$ & - & - & $\$ 2,073$ & - & - & $\$ 2,073$ \\
\hline
\end{tabular}


Table 1 Medical Library Association schedule of changes in net assets by fund year ended December 31, 2017 (continued)

\begin{tabular}{|c|c|c|c|c|c|c|}
\hline & $\begin{array}{c}\text { Net assets } \\
\text { January 1, } \\
2017\end{array}$ & $\begin{array}{c}\text { Contributions } \\
\text { and other } \\
\text { revenue }\end{array}$ & $\begin{array}{c}\text { Invest- } \\
\text { ment } \\
\text { income }\end{array}$ & $\begin{array}{l}\text { Net assets } \\
\text { released } \\
\text { from } \\
\text { restrictions }\end{array}$ & Expenses & $\begin{array}{c}\text { Net assets } \\
\text { December } \\
31,2017\end{array}$ \\
\hline $\begin{array}{l}\text { Cunningham Memorial } \\
\text { International } \\
\text { Fellowship Endowment }\end{array}$ & $\$ 29,925$ & - & $\$ 13,688$ & - & - & $\$ 43,613$ \\
\hline $\begin{array}{l}\text { Louise Darling Medal } \\
\text { for Distinguished } \\
\text { Achievement in } \\
\text { Collection } \\
\text { Development in the } \\
\text { Health Sciences } \\
\text { Endowment }\end{array}$ & $\$ 42,735$ & - & $\$ 5,957$ & $(\$ 1,000)$ & - & $\$ 47,692$ \\
\hline $\begin{array}{l}\text { Janet Doe Lectureship } \\
\text { Endowment }\end{array}$ & $\$ 30,162$ & - & $\$ 4,292$ & $(\$ 2,200)$ & - & $\$ 32,254$ \\
\hline $\begin{array}{l}\text { Carla J. Funk } \\
\text { Governmental } \\
\text { Relations Award } \\
\text { Endowment }\end{array}$ & $\$ 1,639$ & - & $\$ 2,529$ & - & - & $\$ 4,168$ \\
\hline $\begin{array}{l}\text { Eugene Garfield } \\
\text { Research Fellowship } \\
\text { Endowment }\end{array}$ & $(\$ 3,408)$ & - & $\$ 20,606$ & $(\$ 5,000)$ & - & $\$ 12,198$ \\
\hline $\begin{array}{l}\text { T. Mark Hodges } \\
\text { International Service } \\
\text { Award Endowment }\end{array}$ & $\$ 226$ & - & $\$ 274$ & $(\$ 500)$ & - & - \\
\hline $\begin{array}{l}\text { Hospital Libraries } \\
\text { Section/MLA } \\
\text { Professional } \\
\text { Development Grant } \\
\text { Endowment }\end{array}$ & $\$ 18,087$ & - & $\$ 4,576$ & $(\$ 800)$ & - & $\$ 21,863$ \\
\hline $\begin{array}{l}\text { David A. Kronick } \\
\text { Traveling Fellowship } \\
\text { Endowment }\end{array}$ & $(\$ 1,712)$ & - & $\$ 3,712$ & $(\$ 2,000)$ & - & - \\
\hline $\begin{array}{l}\text { Joseph Leiter } \\
\text { NLM/MLA } \\
\text { Lectureship } \\
\text { Endowment }\end{array}$ & $\$ 30,784$ & - & $\$ 6,807$ & - & - & $\$ 37,591$ \\
\hline $\begin{array}{l}\text { Librarians without } \\
\text { Borders } \AA^{\circledR} \text { Ursula } \\
\text { Poland International } \\
\text { Scholarship } \\
\text { Endowment }\end{array}$ & $\$ 3,137$ & - & $\$ 3,733$ & $(\$ 1,000)$ & - & $\$ 5,870$ \\
\hline $\begin{array}{l}\text { Donald A. B. Lindberg } \\
\text { Research Fellowship } \\
\text { Endowment }\end{array}$ & $\$ 64,957$ & - & $\$ 35,763$ & - & - & $\$ 100,720$ \\
\hline $\begin{array}{l}\text { Majors/MLA Chapter } \\
\text { Project of the Year } \\
\text { Endowment }\end{array}$ & $\$ 7,169$ & - & $\$ 1,894$ & $(\$ 1,000)$ & - & $\$ 8,063$ \\
\hline
\end{tabular}


Table 1 Medical Library Association schedule of changes in net assets by fund year ended December 31, 2017 (continued)

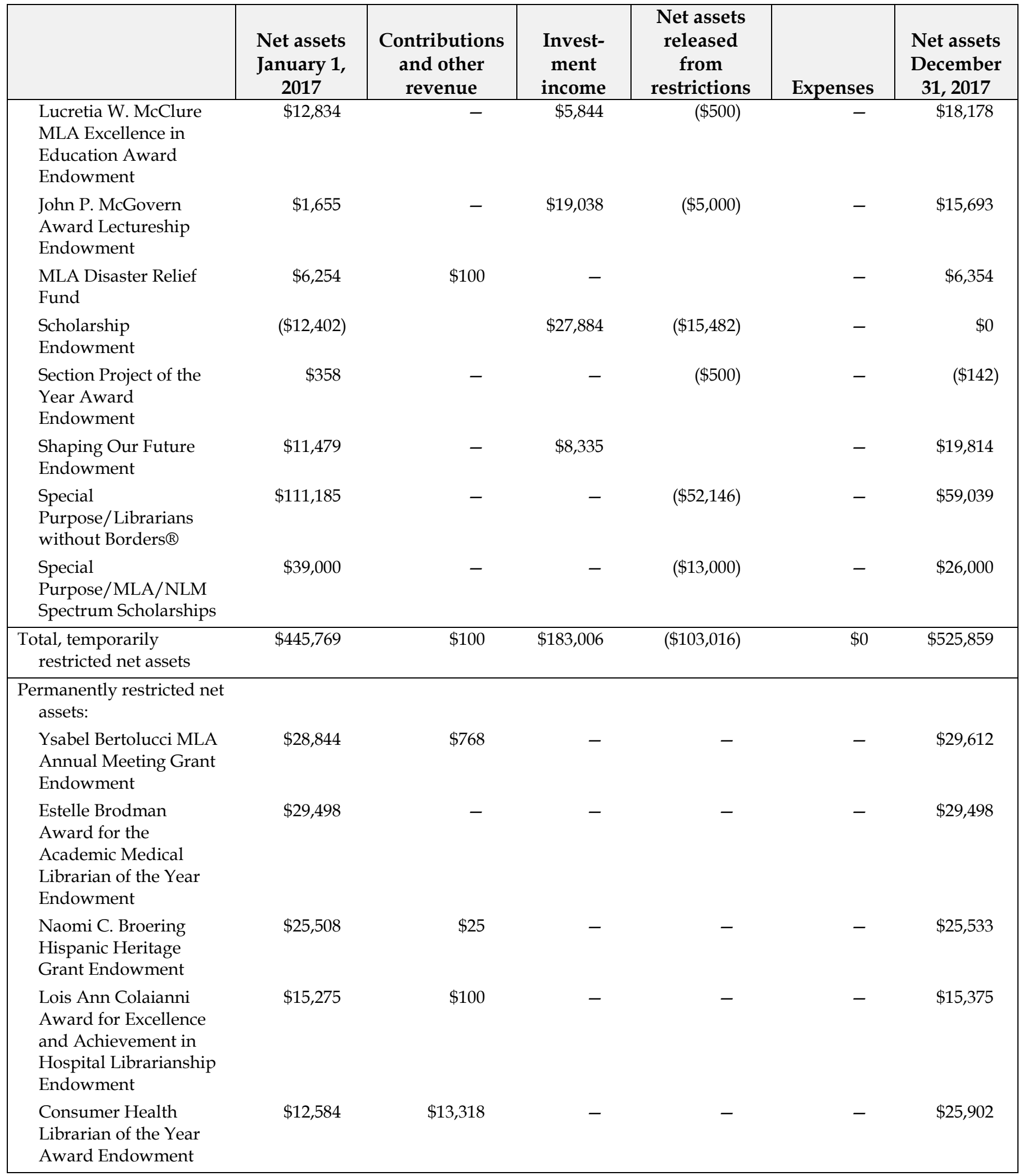


DOI: dx.doi.org/10.5195/jmla.2018.590

Table 1 Medical Library Association schedule of changes in net assets by fund year ended December 31, 2017 (continued)

\begin{tabular}{|c|c|c|c|c|c|c|}
\hline & $\begin{array}{c}\text { Net assets } \\
\text { January 1, } \\
2017\end{array}$ & $\begin{array}{l}\text { Contributions } \\
\text { and other } \\
\text { revenue }\end{array}$ & $\begin{array}{c}\text { Invest- } \\
\text { ment } \\
\text { income }\end{array}$ & $\begin{array}{l}\text { Net assets } \\
\text { released } \\
\text { from } \\
\text { restrictions }\end{array}$ & Expenses & $\begin{array}{c}\text { Net assets } \\
\text { December } \\
31,2017\end{array}$ \\
\hline $\begin{array}{l}\text { Cunningham Memorial } \\
\text { International } \\
\text { Fellowship Endowment }\end{array}$ & $\$ 123,071$ & - & - & - & - & $\$ 123,071$ \\
\hline $\begin{array}{l}\text { Louise Darling Medal } \\
\text { for Distinguished } \\
\text { Achievement in } \\
\text { Collection } \\
\text { Development in the } \\
\text { Health Sciences } \\
\text { Endowment }\end{array}$ & $\$ 36,168$ & - & - & - & - & $\$ 36,168$ \\
\hline $\begin{array}{l}\text { Janet Doe Lectureship } \\
\text { Endowment }\end{array}$ & $\$ 26,059$ & $\$ 300$ & - & - & - & $\$ 26,359$ \\
\hline $\begin{array}{l}\text { Carla J. Funk } \\
\text { Governmental } \\
\text { Relations Award } \\
\text { Endowment }\end{array}$ & $\$ 15,353$ & $\$ 1,100$ & & & & $\$ 16,453$ \\
\hline $\begin{array}{l}\text { Eugene Garfield } \\
\text { Research Fellowship } \\
\text { Endowment }\end{array}$ & $\$ 125,101$ & - & - & - & - & $\$ 125,101$ \\
\hline $\begin{array}{l}\text { T. Mark Hodges } \\
\text { International Service } \\
\text { Award Endowment }\end{array}$ & $\$ 4,865$ & - & - & - & - & $\$ 4,865$ \\
\hline $\begin{array}{l}\text { Hospital Libraries } \\
\text { Section/MLA } \\
\text { Professional } \\
\text { Development Grant } \\
\text { Endowment }\end{array}$ & $\$ 27,781$ & $\$ 100$ & - & - & - & $\$ 27,881$ \\
\hline $\begin{array}{l}\text { David A. Kronick } \\
\text { Traveling Fellowship } \\
\text { Endowment }\end{array}$ & $\$ 26,990$ & $\$ 276$ & - & - & - & $\$ 27,266$ \\
\hline $\begin{array}{l}\text { Joseph Leiter } \\
\text { NLM/MLA } \\
\text { Lectureship } \\
\text { Endowment }\end{array}$ & $\$ 41,328$ & $\$ 250$ & - & - & - & $\$ 41,578$ \\
\hline $\begin{array}{l}\text { Librarians without } \\
\text { Borders® Ursula } \\
\text { Poland International } \\
\text { Scholarship } \\
\text { Endowment }\end{array}$ & $\$ 22,665$ & $\$ 150$ & - & - & - & $\$ 22,815$ \\
\hline $\begin{array}{l}\text { Donald A. B. Lindberg } \\
\text { Research Fellowship } \\
\text { Endowment }\end{array}$ & $\$ 217,124$ & $\$ 900$ & - & - & - & $\$ 218,024$ \\
\hline $\begin{array}{l}\text { Majors/MLA Chapter } \\
\text { Project of the Year } \\
\text { Endowment }\end{array}$ & $\$ 11,500$ & - & - & - & - & $\$ 11,500$ \\
\hline
\end{tabular}


Table 1 Medical Library Association schedule of changes in net assets by fund year ended December 31, 2017 (continued)

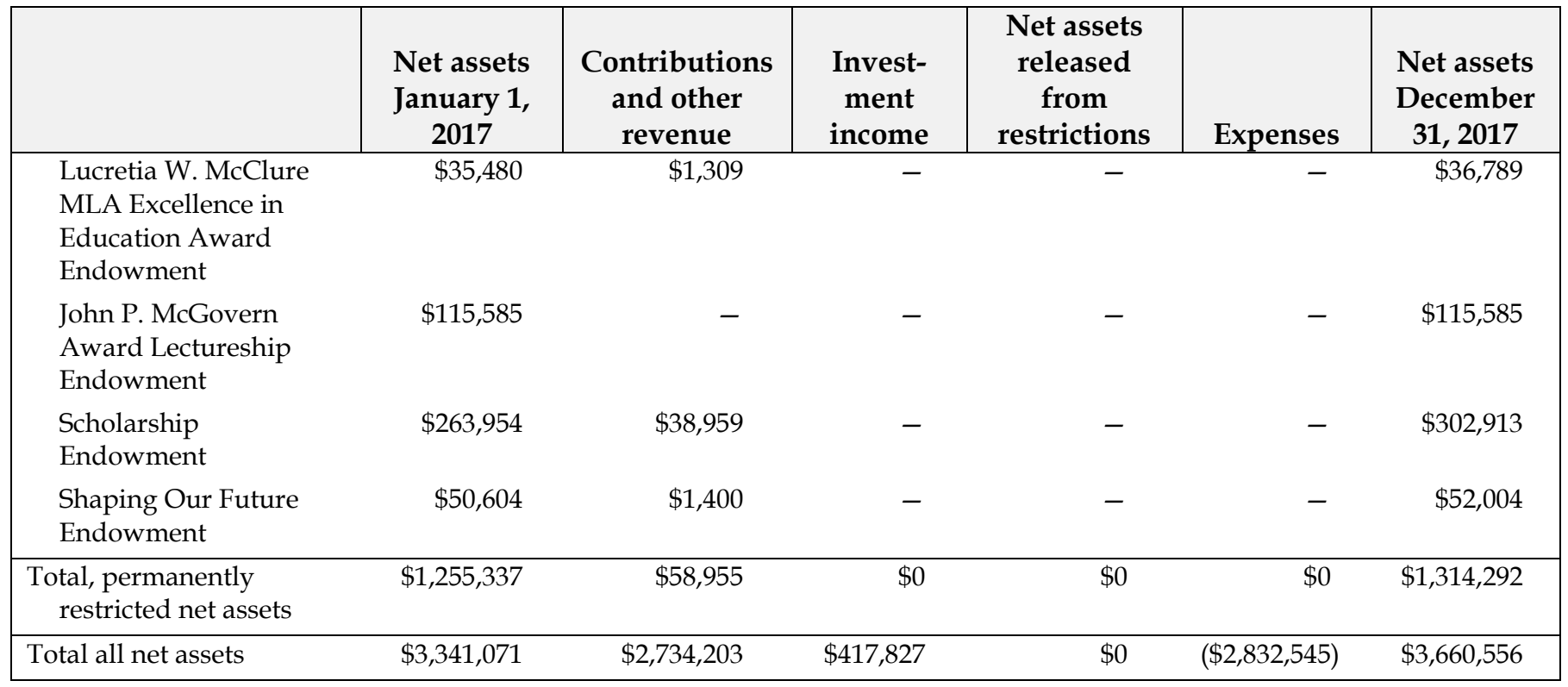

\section{AUTHOR'S AFFILIATION}

Ray Naegele, naegele@mail.mlahq.org, Medical Library Association, 65 East Wacker Place, Suite 1900, Chicago, IL 60601-7246 